\title{
The Impact of Internet Finance on Small And Medium-sized Enterprises Financing in The Context of Big Data
}

\author{
Liang Kaier ${ }^{1}$ \\ ${ }^{1}$ Dalian Vocational Technical College, Zip code: 116035
}

\begin{abstract}
With the continuous development of the times, the financial market environment has undergone tremendous changes, and many small and medium-sized enterprises have begun to transform. Financing difficulties have arisen, which have restricted the further development of small and medium-sized enterprises. Starting from the financing situation, the article mainly discusses the impact of Internet finance on the financing of small and medium-sized enterprises
\end{abstract}

\section{Introduction}

After a period of development, SMEs have experienced market system changes. At present, under the influence of the market economy environment or internal structure, great economic changes have taken place, which makes SMEs face some problems. Therefore, the impact of Internet finance on the financing of SMEs should be actively analyzed to ensure that SMEs can develop in the long term in the future.

\section{The main body of Internet financial platform is established.}

The main body of the Internet financial platform is different from the growth of traditional financial institutions. There are industry barriers in the market of traditional financial institutions, which are monopolized due to the protection of national policies. The deposit interest rate is not market-oriented and the deposit insurance system is not established. The loan business of traditional financial institutions in the seller's market and product and business and model innovation lack source power and competitiveness because their existing businesses are protected by the system with considerable income. With the gradual opening of the financial industry and the rise of Internet companies, Internet financial platforms have a powerful new platform function that connects logistics, information and capital flows based on huge customers and large amounts of data. The emergence of these Internet financial platform entities is the result of making market choices on the basis of correctly understanding customers and the market with the source of continuous innovation and change. The establishment of the main body of the Internet financial platform must be based on the market, and it is up to the market participants to choose between the supply and demand of funds. The government's responsibility is to supervise and serve the Internet financial market. Its principle is to respect market choices and do not interfere and maintain the market well.

For example, crowd funding platform financing model is a new method based on Internet and SNS communication features. Enterprises use the Internet crowd funding financing platform to raise public funds. Small and medium-sized enterprises that require crowd funding can freely publish detailed project plans and business models on the platform, and obtain the target amount within the specified time. In order to prove the success of the crowd funding project with financial support, physical or equity investment in the public is completed. Compared with traditional financing channels, crowd funding has a lower threshold. Relying on a large amount of small financing can reach a certain financing scale. Whether it has commercial value is the only criterion for obtaining financing. For innovative SMEs, crowd funding is not only a low-cost financing method but also a company's unique market feedback and advertising function. It can provide a lot of help for talents and markets in the future industry with certain business valueadded. Although restricted by regulations and other factors, the path of crowd funding has been questioned and its role in solving the financing difficulties cannot be ignored. With the progress of the society, its vast development space needs to be further explored monitored at the legislative. Due to the complexity of Internet finance, regulators must cooperate with each other to form mutual assistance between regulators and the main bodies of Internet finance platforms. The organization form, qualification conditions, risk prevention and other standards should be clear.

For another example, the supply chain finance model starts from the core enterprises, which provides corresponding financial support for disadvantaged SMEs. On the one hand, it can help relatively weak SMEs to solve financing difficulties and supply chain imbalances. On the other hand, it also enhances the business reputation of 
SMEs and promotes the establishment of long-term strategic synergy between SMEs and core leading companies. The difference with traditional financing methods is that the supply chain financial model provides financial services related to all links of the entire supply chain. Companies that occupy large amounts of liquid funds, such as accounts, accounts receivables, and inventories, can borrow from banks through the transfer of accounts receivable and pledge of cargo rights to fully solve the problems of small financing scale and high threshold to achieve flexible capital turnover of enterprises. Secondly,in order to establish an online financial market access system, the vicious competition in the Internet has a negative impact on financial stability, and the exit mechanism stimulates innovation in the main body of the Internet financial platform. Finally, it is needed to strengthen the security management of supplier funds and the Internet For information disclosure of platform entities. The government should strictly monitor Internet financial platform entities through fund security management and information disclosure systems to prevent lawless elements from seeking profits and damaging the balanced of the Internet financial market.

\begin{tabular}{|c|c|c|c|c|c|c|c|}
\hline Platform & $\begin{array}{l}\text { Platform } \\
\text { properties }\end{array}$ & \begin{tabular}{|c|} 
Successful projects \\
(pcs)
\end{tabular} & $\begin{array}{c}\text { Successful } \\
\text { funding (Ten } \\
\text { thousand yuan) }\end{array}$ & $\begin{array}{c}\text { Successful } \\
\text { projects } \\
\text { supported }\end{array}$ & $\begin{array}{c}\text { Support } \\
\text { number of } \\
\text { single } \\
\text { project }\end{array}$ & 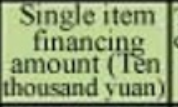 & \begin{tabular}{|c|}
$\begin{array}{c}\text { Total number of } \\
\text { cxisting projects } \\
\text { of the platromm } \\
\text { (pes) }\end{array}$ \\
\end{tabular} \\
\hline Jingdong & Commodity & 271 & 20,621 & 801641 & 2958 & \begin{tabular}{|r|}
76.09 \\
\end{tabular} & \begin{tabular}{|l|}
1000 \\
\end{tabular} \\
\hline Taobao & Commodity & 228 & 11,700 & 1048379 & 4598 & 51.32 & 1131 \\
\hline Green orangc & Commodity & 128 & 2,592 & 45570 & 356 & 20.25 & 160 \\
\hline Suning & Commodity & 20 & 726 & 29373 & 1469 & 36.3 & 80 \\
\hline $\begin{array}{l}\text { Angel } \\
\text { collostion } \\
\end{array}$ & Equity & 310 & 300,000 & 2386 & 8 & 967.74 & 36954 \\
\hline Everyone vote & Equity & 162 & 32,877 & 8698 & 54 & 202.95 & 165 \\
\hline $\begin{array}{l}\text { Ongimal } \\
\text { mestins }\end{array}$ & Equity & 11 & 1,525 & 344 & 31 & 138.64 & 352 \\
\hline Angel streat & Equity & 13 & 3,969 & 5196 & 400 & 305.31 & 30 \\
\hline $\begin{array}{c}\text { Evenbody } \\
\text { vole }\end{array}$ & Equity & 55 & 6,837 & 700 & 13 & 124.31 & 69 \\
\hline
\end{tabular}

Fig1. Statistics of well-known crowd funding platforms in China

\section{New Internet financial profit model}

The era of big data changes, and the basic framework of Internet technology and financial platforms is equipped with search engine capabilities, integrated data, cloud computing models, and social scene platform releases, etc., to increase the balance and the symmetry of the supply and demand of new funds. Big comprehensive data mobile Internet finance and other companies have accumulated a large number of transaction data of all users. It can quickly analyze and mine the daily consumption habits of ordinary users and supplier transaction behaviors to accurately obtain the ability of suppliers and borrowers. The future consumption behavior of users from an angle is a very important new discovery for traditional Chinese finance and domestic institutional enterprises. Financial service product platforms can create real financial value in marketing promotion and potential risks and management of mortgage loans. Secondly, the released third-party payment amount platform is issued by both parties' independent back-end platforms, and the middle part of the platform is released due to its reputation protection. The third-party installment platform provides complete additional information for the cumulative customers, direct payment and settlement. It can provide customers with high-quality services at low cost, which is convenient for small and medium-sized company loans and other services.

For example, $\mathrm{P} 2 \mathrm{P}$ online credit is a new financing model that combines private credit and Internet. An online banking credit platform with relevant qualifications is provided as an intermediary institution, which becomes a bridge between borrowers in the new financing. Internet technology has been able to complete fund raising and transaction to meet the actual needs. As a third-party P2P online credit platform, it can provide credit ratings for other companies and mortgage for companies, and automatically perform comprehensive analysis of data and select the most attractive financing for new companies. For SMEs, P2P online loans include new financing methods (private lending) and become one of the standardized and efficient financing methods, thereby reducing the overall costs of small enterprises and providing them with more and more follow-up funding services. The P2P online lending platform provides consumer credit purchase rating and final price comprehensive evaluation, and the $\mathrm{P} 2 \mathrm{P}$ online private lending platform can provide more collateral. The potential demand side of capital will choose an attractive real interest rate, and its profits are obtained through professional service fees for capital supply and demand. Internet technology and financial websites can provide new forms of marketing and sales channels, including domestic financial institutions and other products, searchable and best-priced financial products, thus continuously strengthening the financial sector. The competition between domestic institutions is conducive to raising market interest rates, which in turn provides better services and capital supply and demand for both parties. It is not difficult to see that the innovative breakthrough of the profit model in the financial field on the Internet is based on how the market can better serve the supply of capital and the potential demand. The fundamental requirements of the authors improve the effectiveness of the capital allocation function. 


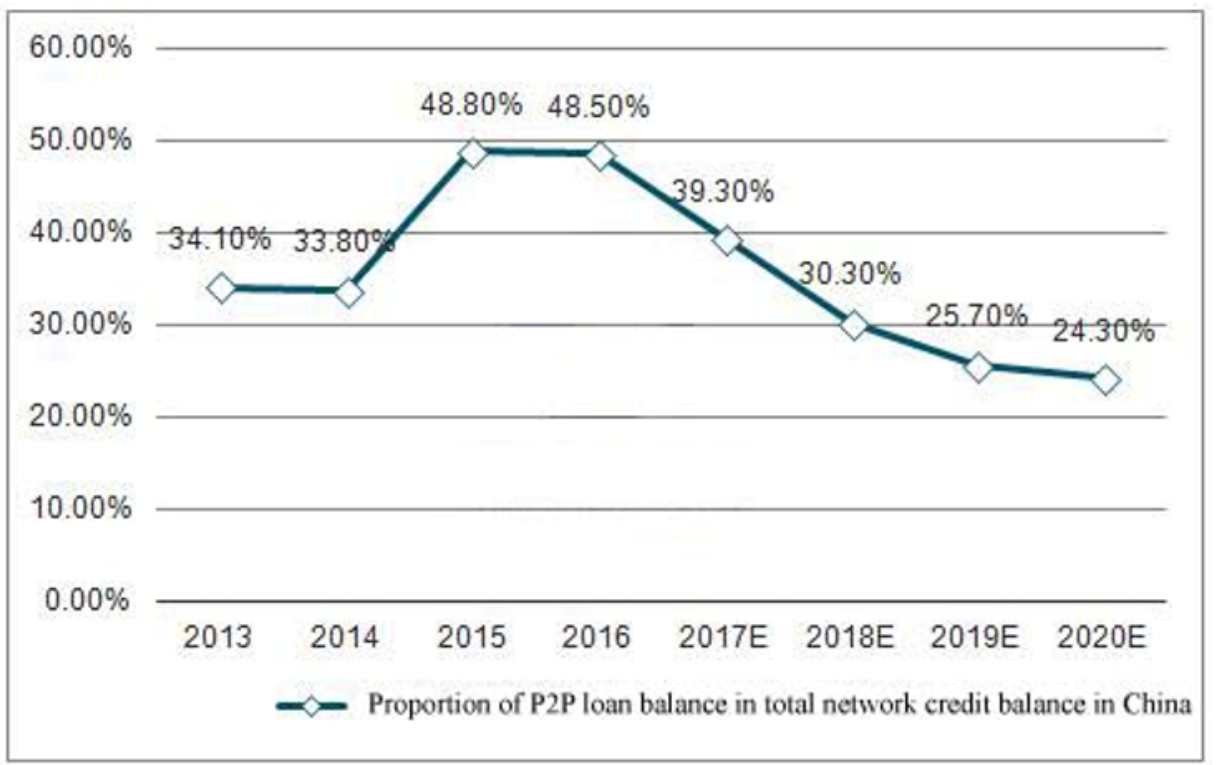

Fig2. The proportion of P2P lending balance in the total online credit balance in China from 2013 to 2020

\section{Provide more financial options for SMEs}

In the context of final big data, there are service products for small businesses inside and the platform outside. Stock investors can also complete upstream and downstream transactions based on comprehensive operating data and key indicators of authoritative certification through the Internet platform. A comprehensive analysis of various data and information of SMEs can be conducted to clarify the comprehensive ability of sustainable innovation. Stock investors can choose to have greater development potential and further increase the price of SME products to meet the actual needs of investors. SMEs should launch targeted products, which will help improve customer return rates. For small and medium-sized enterprises outside the large platform, comprehensive data consumption demand analysis is very difficult to respond to investor consumption needs. According to statistics, Alibaba's small and medium-sized terminal customers have reached 650,000 loans. If the bank's mortgage loan changes in different ways, the financing amount of SMEs will also change. If the value of securities or housing assets is used as collateral, comprehensive analysis of SMEs' comprehensive data will be required. It can be said that in the Internet era, small and medium-sized enterprise investors have been provided with complete and accurate financial services, and effectively solved the urgent and short-term investment problems.

For example, in March 2014, the first batch of five private bank pilots were officially approved. The sources of e-commerce platform funding providers have become diversified. In the future, there will be the following types. The e-commerce platform establishes micro-loan companies, such as Alibaba loans. Secondly, e-commerce platforms use bank licenses to finance, such as Alibaba's micro-loan model; Tencent's micro-loan model. Thirdly, e-commerce platforms are taken as providers. The business platform provides rating, pricing and guarantee services for platform users, which are independently selected by investors. The e-commerce platform uses its own data to provide services for financial institutions as an intermediary, and funds are provided by financial institutions. Whether it is JD Mall, Suning E-commerce and other independent B2C platforms, they buy goods from SMEs suppliers and then sell the goods on their own platforms. In sales and transactions, third parties have accumulated a large amount of data and transaction information, and e-commerce platforms will analyze these data and provide corresponding loan amounts for SMEs. Internet companies can use e-commerce platforms to establish micro-loan enterprises and obtain funds, use ecommerce platforms as platform suppliers, and provide pricing and guarantee services for users. In the actual process of investing in platforms, it mainly have independent $\mathrm{B} 2 \mathrm{C}$ and sales platforms. Among them, independent $\mathrm{B} 2 \mathrm{C}$ platforms mainly purchase products from SME suppliers, and then sell through their own platforms (such as Suning E-commerce, JD Mall). Sales platforms mainly use B2B and B2C e-commerce models, regardless of the type of investment mode. The Ministry of Commerce will generate a large amount of data information in the transaction. E-commerce platforms can use big data technology to analyze the data information and determine the final financing amount according to the analysis results.

\section{Conclusion}

In the development of green finance, it is necessary to make full use of the advantages of Internet finance, make in-depth analysis of customers' credit status with modern science and technology, and strengthen government policy research to further avoid financial risks of small and medium-sized enterprises. 


\section{Acknowledgment}

This article is the achievement of the construction of the 2019 research and innovation of Dalian Vocational and Technical College

\section{References}

1. Lin Wei. 2018. Research of Internet finance and SMEs financing model innovation under the new situation [J]. Technology Economic Market, (05)

2. Xie Lingling.2018. Whether Internet finance can ease the financing constraint of SMEs [J]. Chinese Market, (13)

3. Hou Zhiming, Li Wanqing. 2017. On the financing of SMEs under the background of big data and Internet finance [J]. Financial Economy, (24)

4. Liang Liang. 2018. Research of Internet finance and financing innovation of small and micro enterprises based on big data platform $[\mathrm{J}]$. Accounting Learning, 000 (008): 153-155

5. Wang Na. 2018. Research of financing of small and micro enterprises based on Internet finance [J]. Modern Economic Information, (02): 329

6. Chu Shaner, Gao, Changchun. 2018. Has Internet finance released the financing constraints of cultural and creative enterprises? [J] Journal of Capital University of Economics And Trade, (6): 34-43 